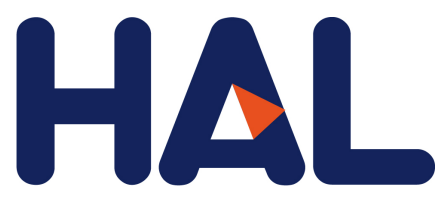

archives-ouvertes

\title{
Anomeric Spiro-Annulated Glycopyranosides: An Overview of Synthetic Methodologies and Biological Applications
}

\author{
Maxime Pommier, Sébastien Vidal
}

\section{To cite this version:}

Maxime Pommier, Sébastien Vidal. Anomeric Spiro-Annulated Glycopyranosides: An Overview of Synthetic Methodologies and Biological Applications. Topics in Heterocyclic Chemistry, Springer Nature, 2019, pp.1-25. 10.1007/7081_2019_33. hal-03006686

\section{HAL Id: hal-03006686 \\ https://hal.archives-ouvertes.fr/hal-03006686}

Submitted on 23 Nov 2020

HAL is a multi-disciplinary open access archive for the deposit and dissemination of scientific research documents, whether they are published or not. The documents may come from teaching and research institutions in France or abroad, or from public or private research centers.
L'archive ouverte pluridisciplinaire HAL, est destinée au dépôt et à la diffusion de documents scientifiques de niveau recherche, publiés ou non, émanant des établissements d'enseignement et de recherche français ou étrangers, des laboratoires publics ou privés. 


\title{
Anomeric Spiro-Annulated Glycopyranosides: An Overview of Synthetic Methodologies and Biological Applications
}

\author{
Maxime Pommier and Sébastien Vidal
}

\section{Contents}

1 Introduction

2 Intramolecular Strategies Toward Spiro-Annulated Carbohydrates

2.1 Through Two Pre-installed Tethers and Without Stereoselective Outcome (Path A)

2.2 Through One Pre-installed Tether and with Stereoselective Outcome (Path B)

3 Intermolecular Synthetic Strategies Toward Spiro-Annulated Carbohydrates

3.1 Strategies Toward Spiro-Annulated Derivatives with Three-Membered Rings (Path C)

3.2 Strategies from C-1 gem-Di-Activated Pyranosides

3.3 Through a Tether and Activation at the Anomeric Position (Path D)

3.4 Through Two Tethers (Path E)

4 Strategies Toward Biologically Active Spiro-Bicyclic Glycopyranosides

4.1 Papulacandin (Path B)

4.2 Tofogliflozin (Path B)

4.3 Synthesis of Spiro-Bicyclic Systems as Potential Glycogen Phosphorylase Inhibitors

5 Conclusion and Perspectives

References

\begin{abstract}
Organic chemistry developed a series of synthetic strategies toward spiro-annulated carbohydrates as potential pharmaceutical drugs or developed new organic synthetic methodologies. The present chapter gives a general overview of the spiro-annulation of carbohydrates at the anomeric position. The main synthetic strategies can be summarized in five paths. Intramolecular cyclizations can be performed through two short tethers with their reactive ends generating the
\end{abstract}

\footnotetext{
M. Pommier and S. Vidal (ه)

Institut de Chimie et Biochimie Moléculaires et Supramoléculaires (UMR 5246),

Université Claude Bernard Lyon 1 and CNRS, Bâtiment Lederer, Villeurbanne, France

e-mail: sebastien.vidal@univ-lyon1.fr
} 
spirocycle or through a single tether reacting at the anomeric position for cyclization. The three other strategies rely on intermolecular reactions with a portion of the spirocycle only in the external substrate or also on the carbohydrate. Radicalmediated cyclization and cycloaddition reactions are the main strategies toward spiro-annulated carbohydrates. A special attention is paid to discussion of the stereocontrol of the anomeric configuration and also to yields in industrial syntheses or biological activities of the molecules. A specific attention is devoted to tofogliflozin and glycogen phosphorylase inhibitors both used as antihyperglycemic drugs and drug candidates, respectively.

Keywords 1,3-Dipolar cycloaddition · Cycloaddition · Glycogen phosphorylase * Hydrogen atom transfer (HAT) · Medicinal chemistry $\cdot$ Radical cyclization · Ring-closing metathesis $\cdot$ SGLT2 $\cdot$ Spiroketal $\cdot$ Spiro-lactam · Type 2 diabetes

\section{Introduction}

Carbohydrates are a major class of natural products with biological implications in bacterial or viral infections, cancer signaling or metastasis, and inflammation. Chemists have intensively investigated the synthesis of not only oligosaccharides for applications in vaccines but also mimetics of monosaccharides for the design of potential drugs or in a medicinal chemistry approach. These efforts have generated literature on the protecting group strategies [1] and also glycosylation methodologies $[2,3]$ for the optimal syntheses of such natural oligosaccharides or glycomimetics. Spiro-annulated carbohydrates are the focus of investigations to design pharmaceutical drugs or to develop new synthetic approaches for their preparation. Natural products such as papulacandin or the recently approved synthetic tofogliflozin as an antihyperglycemic drug used for the treatment of type 2 diabetes are some leading examples in this series (Fig. 1).

Fig. 1 Structure of papulacandin D and tofogliflozin

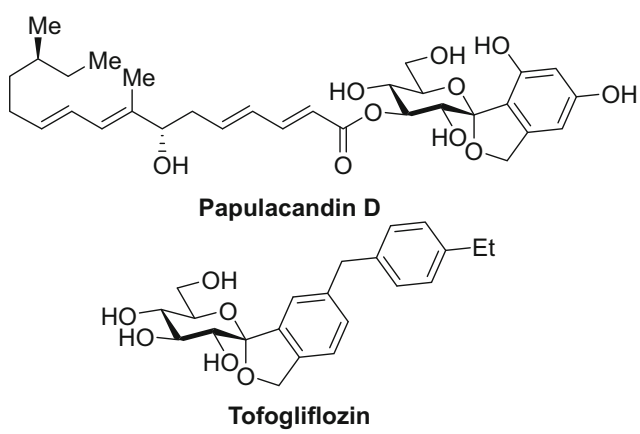


The present chapter is prepared as a general overview of the synthetic strategies reported for the spiro-annulation of carbohydrates at the anomeric position. Typical examples have been selected, and the discussion is not intended to be an exhaustive description of the topic. A specific focus on spiro-annulation of hexopyranoses at the anomeric position will also explain the selected examples described herein, and several additional strategies might be possible toward the same spiro-glycoside discussed. For instance, synthetic strategies based on pyranoside ring closure will not be discussed herein.

The main synthetic strategies toward spiro-annulated glycosides can be summarized in five paths (Fig. 2). The cyclization is the key step reaction and can be performed by pre-installing two reactive moieties (X and Y) with a short tether at the anomeric position (Path A) or a single arm of the spirocycle can be incorporated at the anomeric carbon atom with a reactive end (Y) that will cyclize at the anomeric position (X) (Path B). Paths A and B are intramolecular strategies which are typically more efficient in terms of yields. While Path A will have the stereochemistry of the anomeric center pre-defined in the starting material, the stereoselectivity will need to be controlled under Path B. The other strategies rely on intermolecular reactions with a portion of the spirocycle only in the external substrate (Path $\mathrm{C}$ ) or also on the carbohydrate (Path D). In both Path C and D, the stereochemistry at the anomeric position will have to be controlled. Finally, another strategy creating two bonds (Path E) will not involve the creation of the stereogenic anomeric center with the functionalities already present at the anomeric carbon atom but with addition of a new molecular entity to generate the spirocyclic system. Paths A and E are hence very similar but differ only in the number of chemical bonds created during the cyclization process.

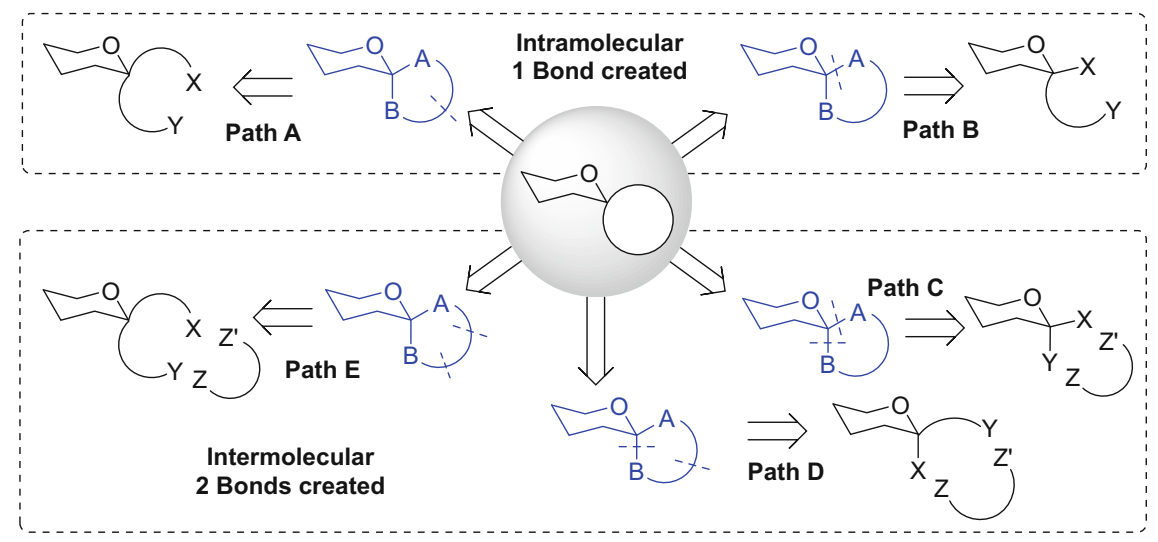

Fig. 2 Spiro-annulation strategies at the anomeric position 


\section{Intramolecular Strategies Toward Spiro-Annulated Carbohydrates}

\subsection{Through Two Pre-installed Tethers and Without Stereoselective Outcome (Path A)}

\subsubsection{Ring-Closing Metathesis}

Ring-closing metathesis is one of the most common and applied cyclization strategies wherein polymerization can be controlled over cyclization by using diluted solutions of substrates and low catalyst loadings. Anomeric 3,3'(glycopyranosylidene)bis(1-propene) (e.g. 1) could be readily converted into the spiro-cyclopentene derivatives 2 via ring-closing metathesis using Grubbs I catalyst from acetylated D-gluco-, D-manno-, or D-galacto-configured precursors (e.g., 1) [4] or Grubbs II catalyst from the benzyl-protected D-gluco- or D-galacto-configured bis-propenes (e.g., 1a) toward the corresponding spiro compounds (e.g., 2a) [5] (Scheme 1).

In a similar approach, the synthesis of spiro-annulated isofagomine analogue 5 could be performed through RCM cyclization of the precursor $C$-vinyl glucoside 3 followed by dihydroxylation of the double bond of intermediate $\mathbf{4}$ and unmasking the protecting groups (Scheme 2) [6]. Spiro-azepanes could also be obtained from the corresponding $C$-allyl glucoside. Some of these compounds were identified as selective yet moderate $\alpha$-mannosidase inhibitors.

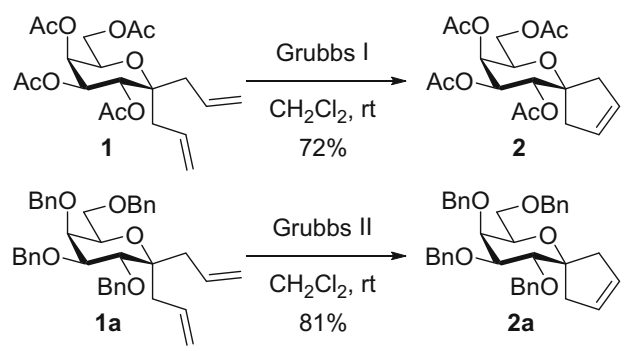

Scheme 1 Spiro-cyclization from bis- $C, C$-allyl glycoside via ring-closing metathesis

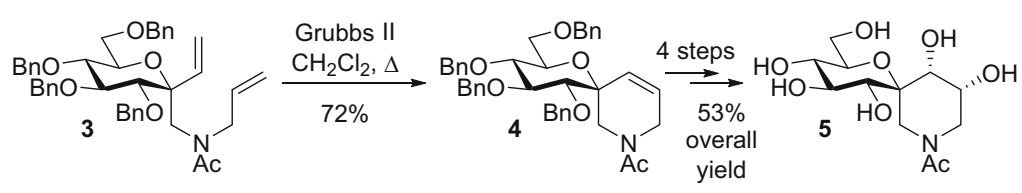

Scheme 2 RCM-mediated spiro-cyclization toward amino sugars 


\subsubsection{Radical-Mediated Ring Closure}

Intramolecular addition of a radical to an allyl glycoside was reported from an (iododeoxy) $O$-allyl ketoside 6 (Scheme 3) [7]. Tributyltin hydride was used as the hydrogen donor, while the radical reaction was triggered thermally using AIBN. The stereochemistry of the anomeric carbon was unchanged from that of the starting material 6, while the configuration of the carbon in the tetrahydrofuran ring bearing the methyl group was clearly identified as depicted from further chemical derivatizations and NMR characterizations. This single isomer 7 was rationalized through a chair-transition-state model and based on the anomeric effects.

Scheme 3 Spiro-

cyclization by intramolecular radicalmediated addition

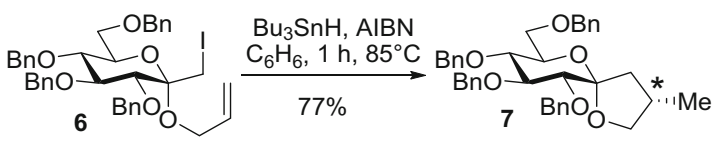

\subsubsection{Spiro-Annulation Toward Crown Ethers}

A 15-crown-5 ether incorporating a spiro-glucoside was synthesized through a lactonization of the carboxylic acid 8 to the lactone 9 (Scheme 4) [8] with potential phase transfer catalytic properties and providing access to chiral crown ether systems. Larger crown ethers could be obtained from glycosylation cyclization strategies [9]. The 15-crown-5 derivative 11 incorporating two spiro-glycosylidene units was prepared from the corresponding disaccharide $\mathbf{1 0}$ through Fraser-Reid glycosylation. The corresponding deprotected chiral crown ethers and larger macrocycles (incorporating more carbohydrate moieties up to four) were then evaluated as asymmetric ligands in Cram model phenyl acetate-acrylate addition with only moderate stereocontrol.

Scheme 4 Cyclization toward spirketal crown ethers

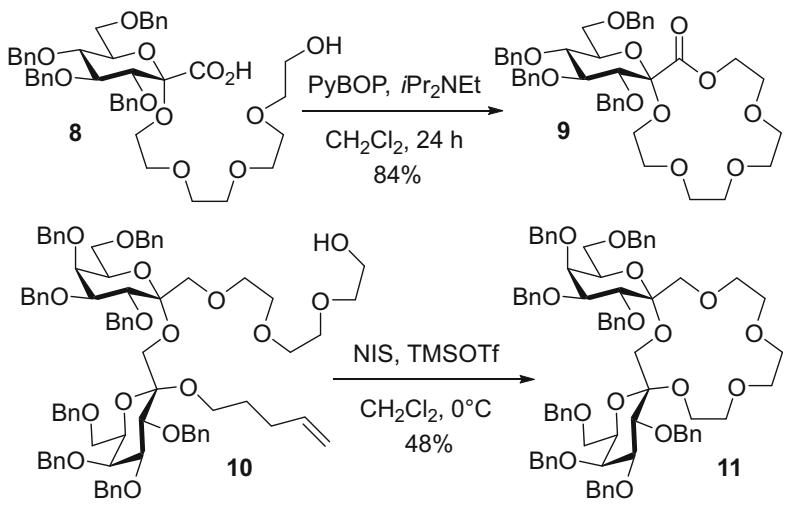




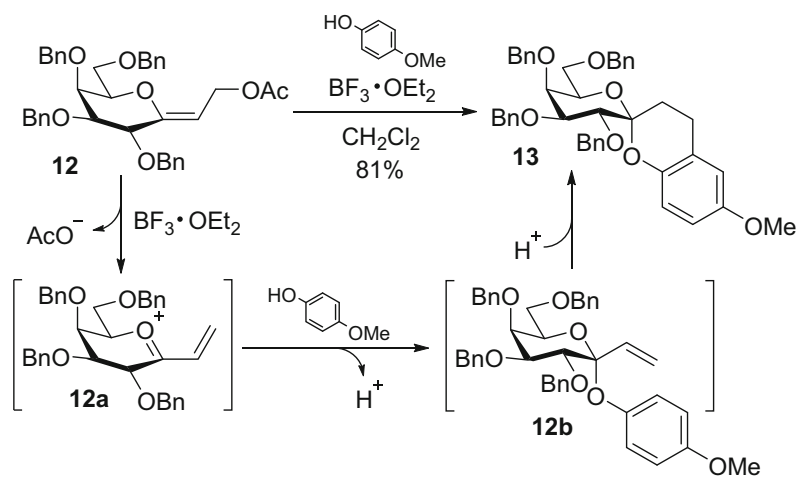

Scheme 5 Spiro-cyclization through a Ferrier-type rearrangement and Friedel-Crafts reaction toward a spiro-pyran

\subsubsection{Ferrier-Type Rearrangement and Friedel-Crafts Strategy}

A two-step process starting from the exo-galactal derivative 12 was designed to access six-membered spiro-annulated galactosides [10] (Scheme 5). The activation of the allyl acetate with boron trifluoride etherate generated a $C$-vinyl oxonium intermediate 12a under a Ferrier-type rearrangement. Nucleophilic substitution with 4-methoxy-phenol led to the $C$-vinyl $O$-galactoside intermediate $\mathbf{1 2 b}$ which upon acid activation underwent an intramolecular Friedel-Crafts reaction to lead to the benzo-fused spiro-galactoside 13.

Access to benzo-fused spiro-cyclopentane $C$-glycosides $\mathbf{1 6}$ was also reported starting from the exo-glycal 14 through Heck-type $C$-arylation to obtain the aldehyde 15 (Scheme 6) [11]. Subsequent Friedel-Crafts spiro-cyclization occurred in the presence of a thiol under $\mathrm{InCl}_{3}$ catalysis. Activation of the aldehyde led to intermediate 15a, and addition of the butanethiol provided the thioacetal 15b. Elimination of the catalyst generated the sulfonium cation 15c which underwent intramolecular Friedel-Crafts-type cyclization to the oxonium ion 15d. Elimination of a proton afforded the desired spiro-glycoside 16. The presence of an electron donating group in the meta position (para to the created bond) on the aromatic ring was required to allow the cyclization. While the Heck-type $C$-arylation was highly $\alpha$-stereoselective, a 3:1 diastereoisomeric ratio was observed for the thioether stereogenic center generated in the reaction. 
Anomeric Spiro-Annulated Glycopyranosides: An Overview of Synthetic...

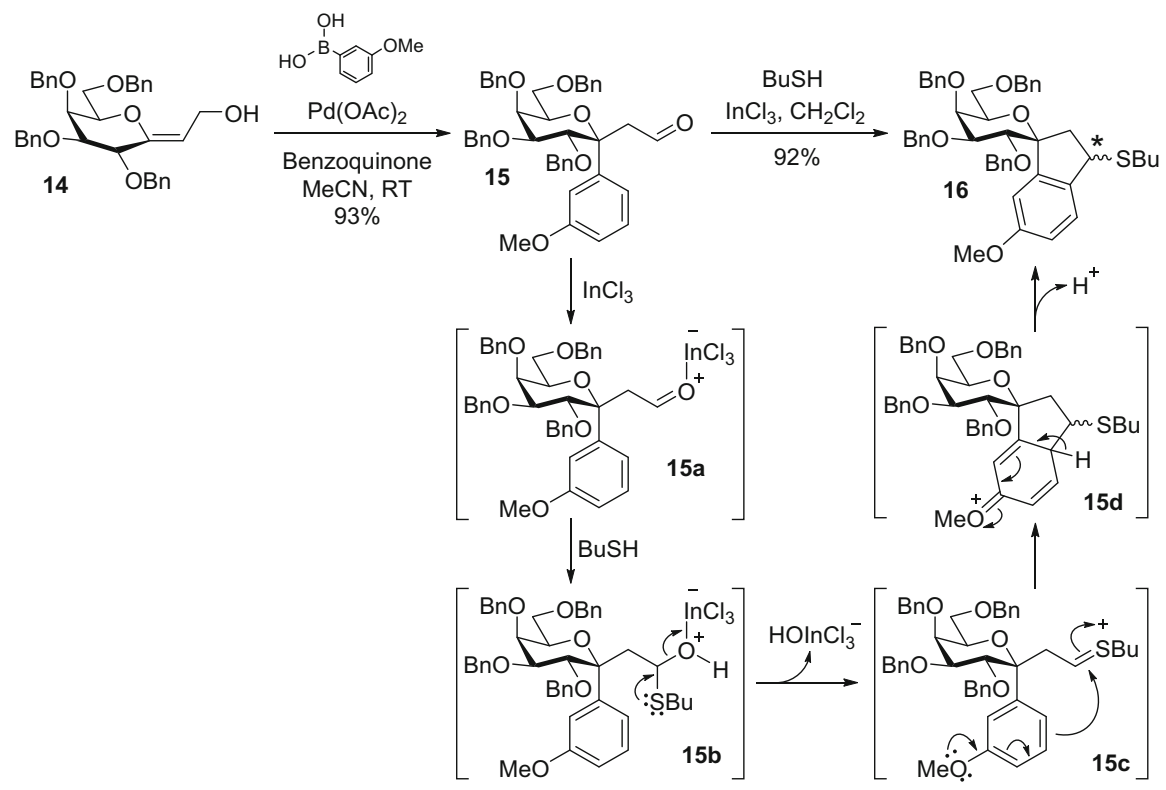

Scheme 6 Spiro-cyclization through a Ferrier-type rearrangement and Friedel-Crafts reaction toward a benzo-fused spiro-pentane

\subsubsection{Spiro-Lactamization}

The ketosyl azide $\mathbf{1 7}$ was reacted under reductive conditions to generate in situ a hemiaminal whose amine moiety led to the spiro-lactams $18 \alpha$ and $18 \beta$ in equimolar ratio (Scheme 7) [12, 13]. Formation of the spiro-epimers can be explained by the anomerization of the hemiaminal intermediate similar to mutarotation for hemiacetals. Six-membered rings could be obtained using the same strategy.

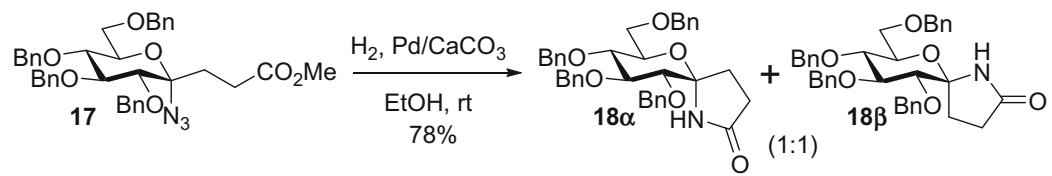

Scheme 7 Spiro-lactamization from a ketosyl azide 

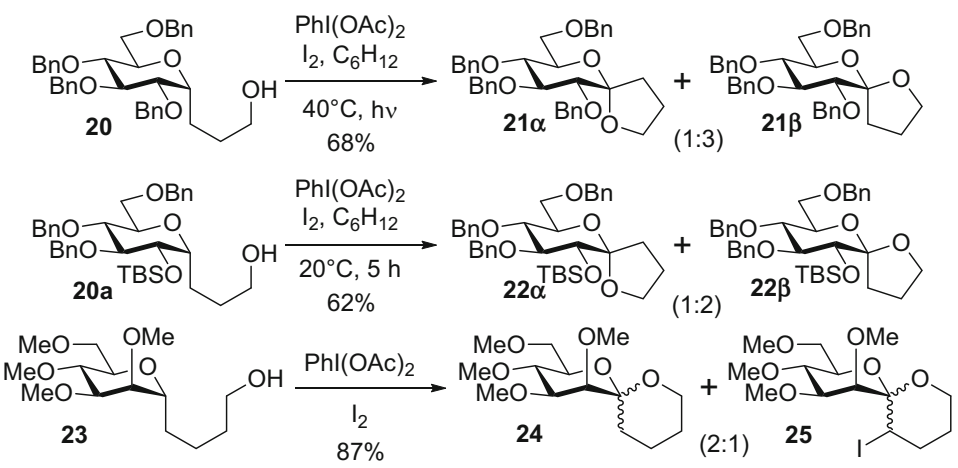

Scheme 8 Spiro-cyclization through hydrogen atom transfer (HAT) to alkoxyl radicals

\subsection{Through One Pre-installed Tether and with Stereoselective Outcome (Path B)}

\subsubsection{Radical-Mediated Spiro-Annulation}

Intramolecular hydrogen atom transfer (HAT) to alkoxyl radicals from the anomeric position of a $C$-glucoside $\mathbf{2 0}$ appeared as a reliable access to spiro-furans $\mathbf{2 1 \alpha}$ and $\mathbf{2 1 \beta}$ with moderate stereocontrol (1:3 ratio) in a short synthetic sequence and in good yield (Scheme 8) [14]. The protecting group pattern around the pyranose ring was found to influence the outcome of the reaction since a 3,4,6-tri- $O$-benzyl-2- $O$ - $t$ butyldimethylsilyl- $C$-glucopyranoside 20a gave an $\alpha / \beta$ 1:2 ratio of spiro-furans $22 \alpha$ and $22 \beta$ with $62 \%$ yield [15]. On the other hand, the $O$-permethylated $C$-mannoside $\mathbf{2 3}$ gave four compounds as epimeric mixtures of spiro-pyran $\mathbf{2 4}$ and 3-iodinated spiro-pyran 25 [16].

The same HAT strategy could be applied to phosphoramidate $\mathbf{2 6}$ through a nitrogen-centered radical (Scheme 9) [17]. The hydrogen abstraction involves the $\beta$-hydrogen atom at the anomeric carbon atom, while the nucleophilic cyclization of the nitrogen moiety occurs on the less hindered $\alpha$-face leading to the spiro-aminal 27. The $C$-mannosyl amide $\mathbf{2 8}$ could also react under HAT conditions to lead to the spiro-lactam 29 in good yield and with high stereocontrol [18]. It is worth pointing out that in the case of such amide used as the nucleophile in the HAT cyclization, the $O$ - or $N$-cyclization product can be observed, but the $O$-cyclization would occur only with carba-sugars (carbon atom replacing the endocyclic oxygen), and the pyranoside would selectively provide the spiro-lactams [18]. 
Anomeric Spiro-Annulated Glycopyranosides: An Overview of Synthetic...

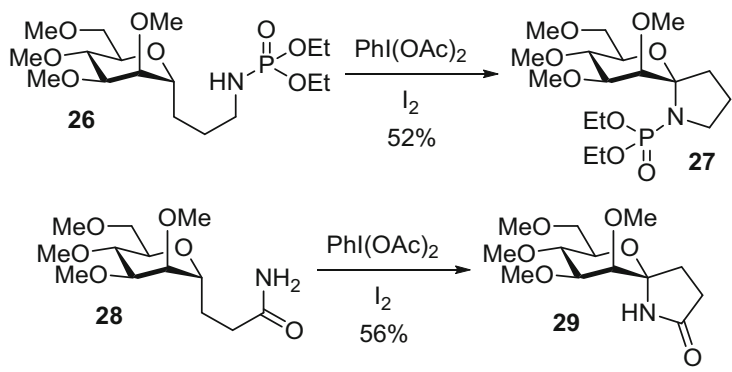

Scheme 9 Spiro-cyclization through hydrogen atom transfer (HAT) to nitrogen-centered radicals

\subsubsection{Spiro-Annulation Through C-H Activation}

An anomeric C-H activation of a $C$-(2-deoxy-glycosyl) carboxamide $\mathbf{3 0}$ afforded a spiro-oxindole derivative $\mathbf{3 1}$ with a moderate diastereoselectivity $(\mathrm{dr}=3: 2)$ (Scheme 10) [19].

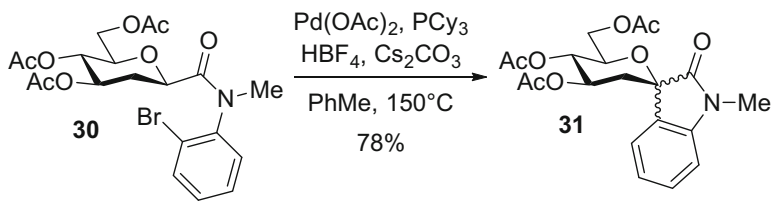

Scheme 10 Spiro-cyclization through anomeric C-H activation

\subsubsection{Spiro-Lactonization on a Sialic Acid Scaffold}

$\mathrm{SmI}_{2}$-Mediated intramolecular spiro-cyclization of the thiosialoside $\mathbf{3 2}$ provided a robust access to the sialic acid-derived spiro- $\delta$-lactone $\mathbf{3 3}$ as a $1: 1$ mixture of diastereoisomers on the newly created stereogenic carbon atom (Scheme 11) [20]. Five- and seven-membered ring lactones could not be obtained through this strategy probably due to steric constraints of the samarium enolate intermediate.

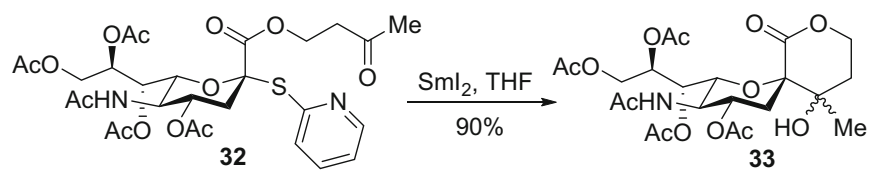

Scheme 11 Spiro-cyclization from sialic acid scaffolds 


\section{Intermolecular Synthetic Strategies Toward Spiro-Annulated Carbohydrates}

\subsection{Strategies Toward Spiro-Annulated Derivatives with Three-Membered Rings (Path C)}

Glycosylidene-spiro-diazirines $\mathbf{3 6}$ are precursors of glycosylidene carbenes which can then be reacted with various electrophiles. The synthesis of such diazirines started from [(glycosylidene)amino]methanesulfonates $\mathbf{3 4}$ to the diaziridine $\mathbf{3 5}$ (actually a Path D-type reaction) which were then oxidized to the diazirines 36 (Scheme 12) [21]. Both compounds $\mathbf{3 5}$ and $\mathbf{3 6}$ could be crystallized from the reaction mixtures. The glycosylidene diaziridines $\mathbf{3 5}$ could be also characterized through its crystallographic structure and displayed slightly shorter $\mathrm{C}-\mathrm{N}$ bond lengths and slightly longer N-N bond length when compared to noncyclic C-N and N-N bond lengths [22].

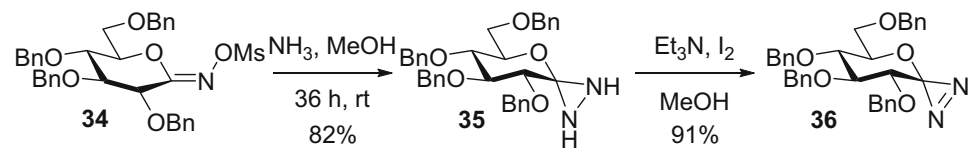

Scheme 12 Synthesis of glycopyranosylidene-spiro-diazirines

Such glycosylidene carbene precursors could then be applied to the synthesis of glycosylidene cyclopropane derivatives (Scheme 13). The reaction of diazirine 36 under photolysis conditions provided a mixture of all four possible regio- and stereoisomers 37a and 37b [23, 24]. The same cyclopropane derivatives 37a-b could be obtained by the photolysis of tosylhydrazone salt $\mathbf{3 8}$ [23, 25]. The acetylated spiro-cyclopropanes $\mathbf{4 0 a}$ and $\mathbf{4 0 b}$ were prepared from the diazido-glucoside 39 as a mixture of four diastereoisomers [26]. Such glycosylidene cyclopropane scaffolds were identified as glycosidase inhibitors [27].

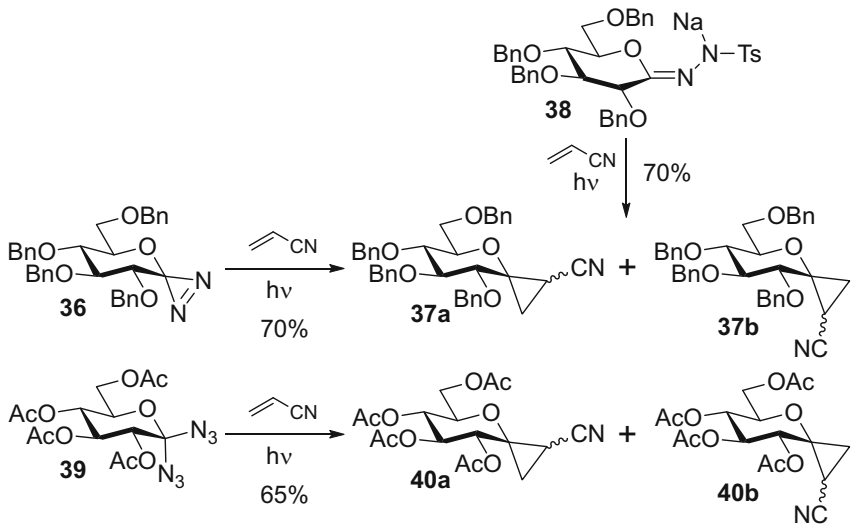

Scheme 13 Synthesis of glycopyranosylidene-spiro-cyclopropanes under photochemical conditions 
Glycosylidene cyclopropanes could also be accessed by [2+1] cycloaddition of ethyl diazoacetate with exo-glycal 41 (although through Path D) to afford the corresponding cyclopropane derivative 42 (Scheme 14) [28]. Although the stereochemistry of the cycloaddition could not be controlled, the reduction and then rearrangement under 2-iodoxybenzoic acid (IBX) activation led to the spiro-furan derivative $\mathbf{4 3}$ again without stereocontrol.

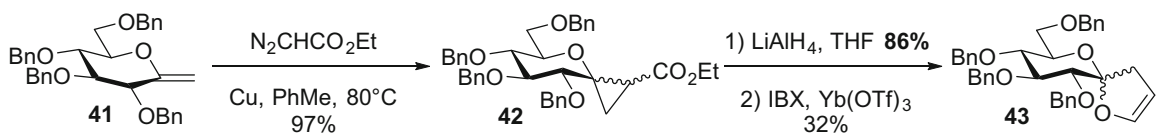

Scheme 14 Synthesis of glycopyranosylidene-spiro-cyclopropanes from exo-glycal and conversion into spiro-furan derivatives

The reaction of diazirine $\mathbf{3 6}$ under either thermolysis [29] or photolysis conditions in the presence of acetone led to the spiro-epoxide 44 without stereocontrol (Scheme 15) [30]. Similar epoxides could be obtained from the oxidation of exoglycal 41 with DMDO (reaction type of Path D) to afford epoxide 45 as a mixture of diastereomers [31]. Reaction of the anion, obtained by lithiation of methyl bromoacetate, with the benzylated gluconolactone $\mathbf{4 6}$ afforded yet another pathway to the epoxide 47 with good stereocontrol (path D) [32-36].

Scheme 15 Synthetic strategies toward glycopyranosylidene-spiroepoxides
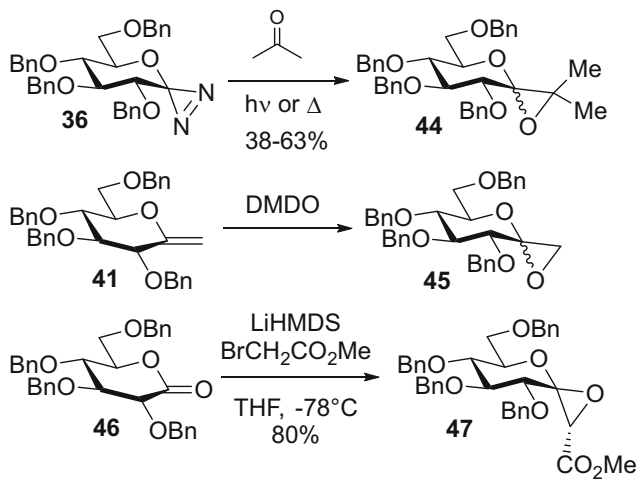

\subsection{Strategies from C-1 gem-Di-Activated Pyranosides}

gem-Bromo-chloro glucopyranose 48 was reacted with ethylene glycol in the presence of silver triflate and sym-collidine used as a base to generate a first "glycosylation" with an intermolecular substitution of alcohol at the anomeric carbon atom, followed by an intramolecular second "glycosylation" to obtain the orthoester 49a (Scheme 16) [37, 38]. The same reaction when performed with catechol required the absence of sym-collidine to afford the benzo-fused 
spiro-orthoester 50. sym-Collidine was suspected to oxidize catechol to the corresponding $o$-quinone. Inter- and intramolecular reactions are competing in this cyclization process as verified by the $65 \%$ yield of compound 49a obtained with ten equivalents of ethylene glycol while a larger excess (90 equivalents) provided a much lower yield (9\%) of the same compound, while the bis-ethylene glycol product represented $43 \%$ yield. A similar approach from the bromo-cyano-galactose $\mathbf{5 1}$ exemplified the use of cyanide as a leaving group to obtain the spiro-galactoside 49b [39]. The access to the 2-deoxy series 49c was reported from the corresponding 2-deoxy-1-bromo-glucosyl cyanide [39] and also from tri- $O$-acetyl-glucal $\mathbf{5 2}$ under $\mathrm{Pd} / \mathrm{Cu}$ catalysis via a Wacker-type mechanism [40].

Scheme 16 Access to spiro-orthoesters (or ortholactones) from gem-di-activated glycosides glycals (ligand $=N, N, N^{\prime}$, $N^{\prime}$-tetramethyl-1,2-transcyclohexanediamine)

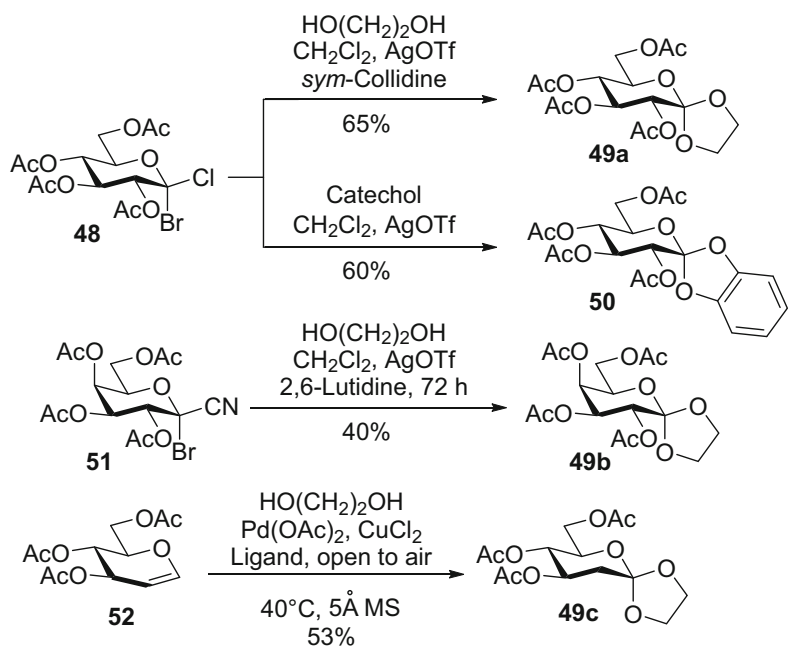

\subsection{Through a Tether and Activation at the Anomeric Position (Path D)}

The peracetylated sialic acid $\mathbf{5 3}$ was reacted with carbodiimides to afford spirohydantoins 54 in high yields (Scheme 17) [41]. The reaction proceeded through a one-pot sequential process with carbodiimides adding to the carboxylic acid and then boron trifluoride etherate induced intramolecular $N$-sialylation with high $\alpha$-selectivity.

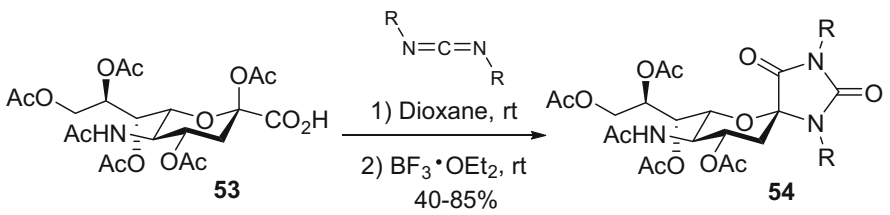

Scheme 17 Spiro-cyclization from sialic acid scaffolds 


\subsection{Through Two Tethers (Path E)}

\subsubsection{Cycloaddition Reactions}

The $[2+2+2]$ cycloaddition strategy of alkynes could be readily applied for the synthesis of spiro-annulated glucosides under either rhodium [42] or ruthenium catalysis [43]. The cycloaddition of the propargyl ketoside with a 1,2-triple bond 55 with acetylene afforded the desired benzo-fused spiro-glucoside 56 in high yields (Scheme 18). Technically, this reaction scheme could also be classified under Path A when considering the creation of only one carbon-carbon bond in the benzene ring.

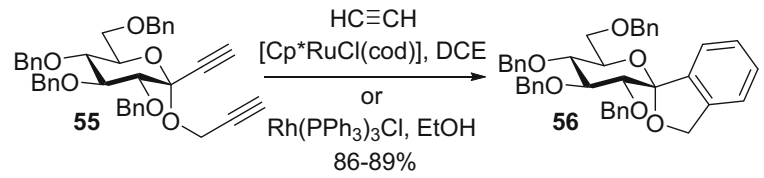

Scheme $18[2+2+2]$ spiro-annulation

A Diels-Alder [4 + 2] cycloaddition strategy was described for the synthesis of a six-membered ring spiro-glucoside (Scheme 19) [44]. The exo-glucal 41 was used as a dienophile with the diene $\mathbf{5 8}$ generated in situ by simple treatment of the diketone 57 with a weak base (pyridine) to trigger the elimination of phthalimide. The mixture of epimers $\mathbf{5 9} \boldsymbol{\alpha}$ and $\mathbf{5 9 \beta}$ was obtained in $91 \%$ yield although with 2.5:1 ratio of separable isomers.

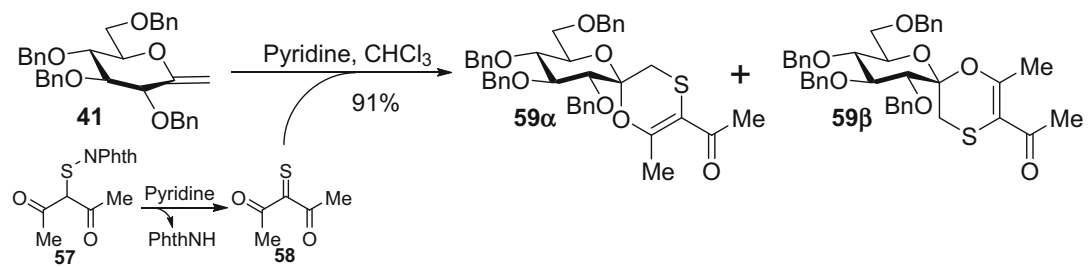

Scheme $19[4+2]$ spiro-annulation from an exo-glycal

\subsubsection{Triphosgene Addition}

Five-membered heterocyclic spiro-bicyclic glycosides can be readily obtained by ring closure on the amino-deoxy ketose 60 using a phosgene equivalent (triphosgene) (Scheme 20) [45, 46]. The conjugation of triphosgene with both the hemiacetal alcohol and the amine moieties provided the spiro-bicyclic carbamate $\mathbf{6 1}$ in high yields with a series of substituents on the amine group. It is worth pointing out that this cyclization occurred on the unprotected carbohydrate. 


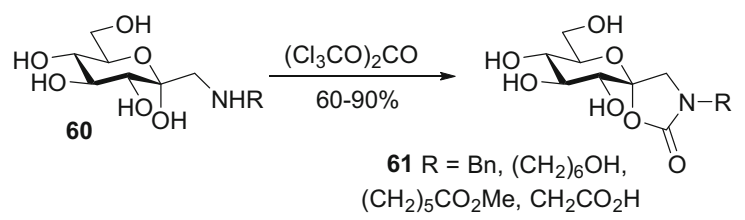

Scheme 20 Spiro-cyclization from a heptose-based Amadori rearrangement product

\section{Strategies Toward Biologically Active Spiro-Bicyclic Glycopyranosides}

\subsection{Papulacandin (Path B)}

Papulacandin is a glycolipid with potent antifungal activities with a benzo-fused spiroketal moiety on a glucopyranose scaffold (Scheme 21). The total synthesis reported by Denmark will be discussed briefly herein as this was one of the first reports to describe an interesting 1,2-epoxide on the pyranose ring. This synthesis was based on an esterification at position 3 of the glucopyranose ring, and hence the other key step was the creation of the spiro-annulated glucopyranose (Scheme 21) $[47,48]$. The $C$-aryl glucal 62 was converted into the corresponding epoxide $\mathbf{6 3}$ with $m$-chloroperbenzoic acid in the presence of a base $\left(\mathrm{NaHCO}_{3}\right)$ to avoid the spiroketalization with the benzylic alcohol on the glucal, prior to the epoxidation. Epoxidation was highly stereoselective for the $\alpha$-face, and the resulting configuration of C-2 could be ascertained from NMR experiments [48]. This epoxide could then undergo spiro-ketalization in situ leading to compounds $64 \alpha$ and $64 \beta$ in a $5: 1$ diastereoisomeric ratio. The $\beta$-anomer $64 \beta$ could be readily converted into the desired $\alpha$-anomer $64 \alpha$ in the presence of hydrochloric acid under thermodynamic control.

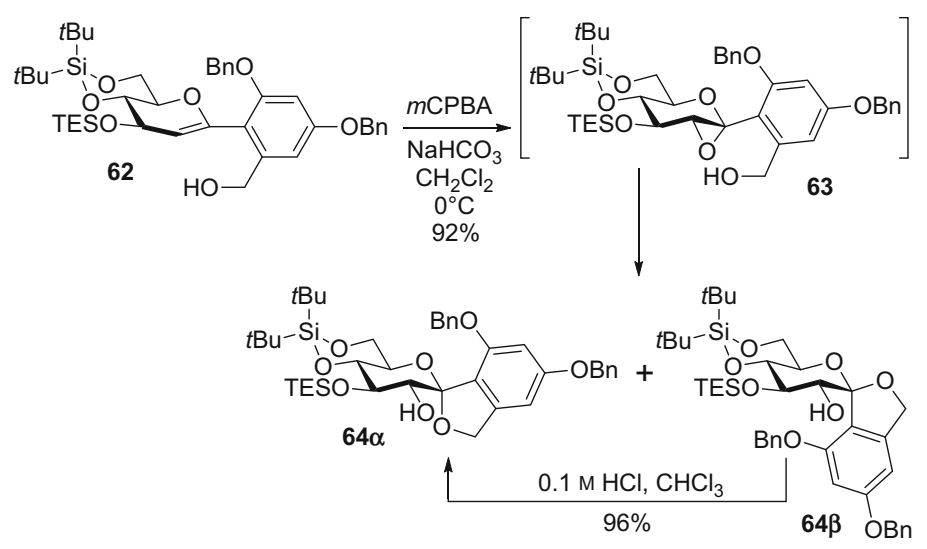

Scheme 21 Exemplary synthesis of papulacandin D 


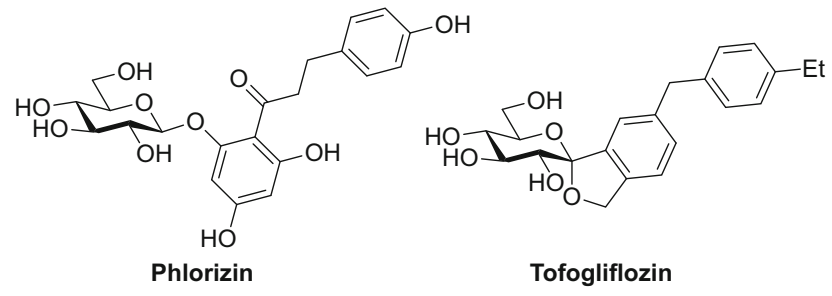

Fig. 3 Phlorizin and gliflozins as SGLT2 inhibitors

\subsection{Tofogliflozin (Path B)}

Glucose transporters are targets to control glycemia as they allow glucose to cross cell membranes. Among those proteins, sodium-dependent glucose transporters (SGLTs) play an important role for glucose absorption and renal reabsorption. They are located in the small intestine (SGLT1) and in the proximal tubule (SGLT1 and SGLT2) of the nephron. SGLTs use the energy of the sodium gradient to transport glucose across the apical membrane, against the uphill glucose gradient, via a symport mechanism [49-51].

Under hyperglycemia, SGLTs are saturated and excess of glucose is eliminated in the urine. In patients with type 2 diabetes mellitus (T2DM), SGLT2 is overexpressed and have higher activity. Therefore, less glucose is excreted in the urine leading to a constant hyperglycemia in the blood stream. Hence, a control of hyperglycemia through selective SGLT2 versus SGLT1 inhibition has been investigated to control glycemia.

A class of inhibitors, known as gliflozins marketed since 2013, was inspired by phlorizin known as a natural compound inhibiting glucose transport mediated by SGLTs (Fig. 3) [52-54]. Among those, tofogliflozin was selected for the purpose of this chapter due to its spiro-annulated carbohydrate moiety.

Tofogliflozin was developed by Chugai Pharmaceuticals and is used as a drug for the treatment of T2DM since 2014 [55]. Tofogliflozin is based on a $C$-aryl $\beta$-Dglucoside attached to an aglycon with a spiro-bicycle moiety at the anomeric carbon. The aglycon itself is composed of a diphenylmethane skeleton. Many syntheses of tofogliflozin have already been described in the literature along with challenges going from lab scale $(\sim 100 \mathrm{mg})$ to industrial scale $(\sim 4 \mathrm{~kg})$. The silylated lactone 67 and the aryl moiety $\mathbf{6 6}$ were condensed followed by the construction of the aglycon (Scheme 22) [56]. The spiro-bond was then created in the last steps of the synthesis leading to the crude tofogliflozin after reduction. The silylated lactone $\mathbf{6 7}$ avoided the hydrogenolysis of benzyl ethers in the original procedure disclosed $[57,58]$ and thus circumvented the possible traces of heavy metals and hazardous use of hydrogen. The final preparation of the tetracarbonate 69 as a crystalline solid allowed a simple filtration for the purification of tofogliflozin. 

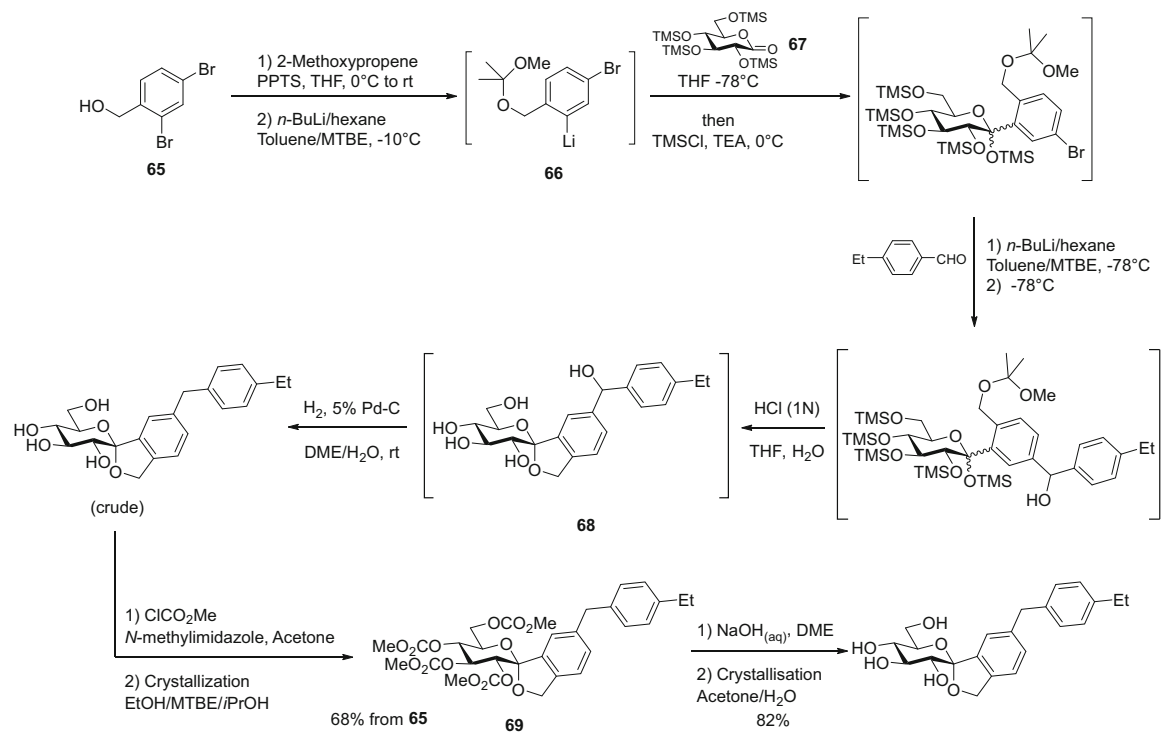

Scheme 22 Lab-scale synthesis of tofogliflozin

Although purification issues were improved from chromatography [57, 58] to crystallization, the use of hydrogen or a highly volatile reagent such as 2-methoxypropene required cautious handling and therefore needed an improvement to conduct an industrial synthesis. Furthermore, the use of palladium catalyst for the hydrogenolysis of $\mathbf{6 8}$ may contaminate the final active pharmaceutical ingredient with traces of the heavy metal. Therefore, a 7-step industrial route toward tofogliflozin has been developed (Scheme 23) [59]. The key steps of this synthetic

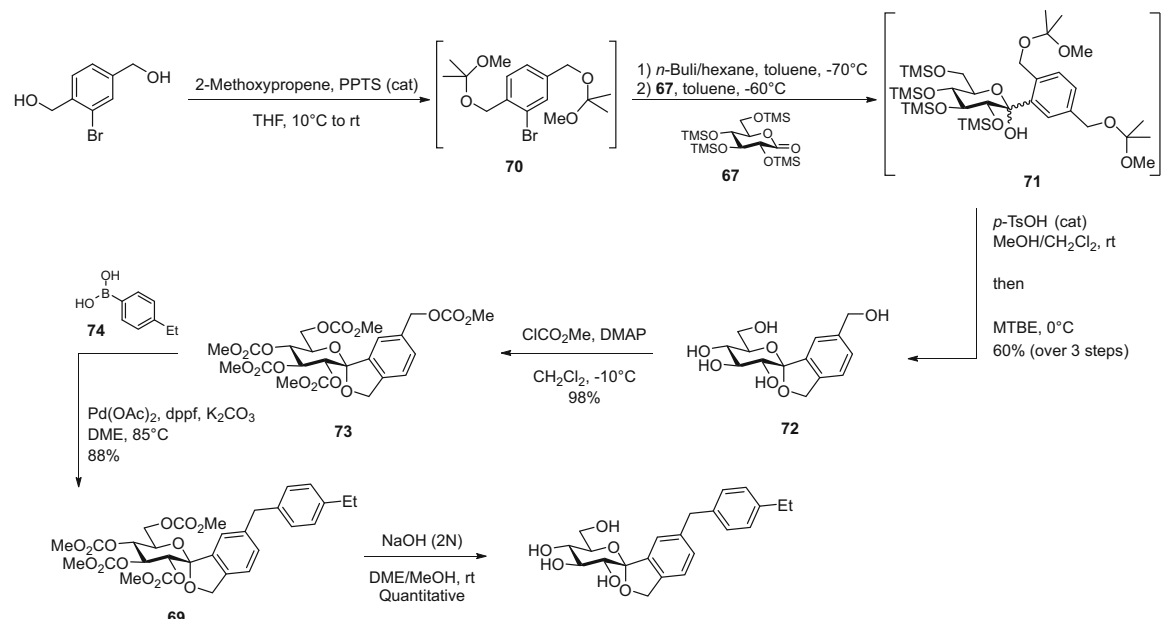

Scheme 23 Scalable $(\sim 50 \mathrm{~g})$ route with safety and purification improvements 
strategy are the formation of the spiroketal intermediate $\mathbf{7 2}$ and then the construction of the methylene bridge to build the aromatic moiety. The protected diol $\mathbf{7 0}$ was condensed with the silylated lactone 67 to give the lactol 71 which was then converted to the desired spiroketal intermediate 72. After a step of protection with carbonate, the formation of the aglycon was performed with a Suzuki coupling of benzyl carbonate $\mathbf{7 3}$ with the corresponding boronic acid $\mathbf{7 4}$ leading to the tetracarbonate of tofogliflozin 69 which was purified by recrystallization. A final step of deprotection afforded the target tofogliflozin in a $52 \%$ overall yield.

A second industrial synthesis was reported through a 12-step sequence including purifications without column chromatography (Scheme 24) [60]. Unlike the previous methodologies, the aryl aglycon was built earlier with a regioselective FriedelCrafts reaction between the acyl chloride $\mathbf{7 5}$ and ethylbenzene. After reduction and protection, the aryl intermediate $\mathbf{7 6}$ was reacted with the silylated lactone $\mathbf{6 7}$ in the presence of $\mathrm{PrMgCl} \cdot \mathrm{LiCl}$ in $\mathrm{THF}$ to form the corresponding lactol 77. Subsequent treatment with $\mathrm{MsOH}$ allowed the spiro-cyclization through the concomitant acidcatalyzed desilylation to afford the crude tofogliflozin. Preparation of the carbonated tofogliflozin 69 allowed the purification by crystallization. Even though there was no further improvement in terms of yield, this methodology required the use of less expensive reagents.

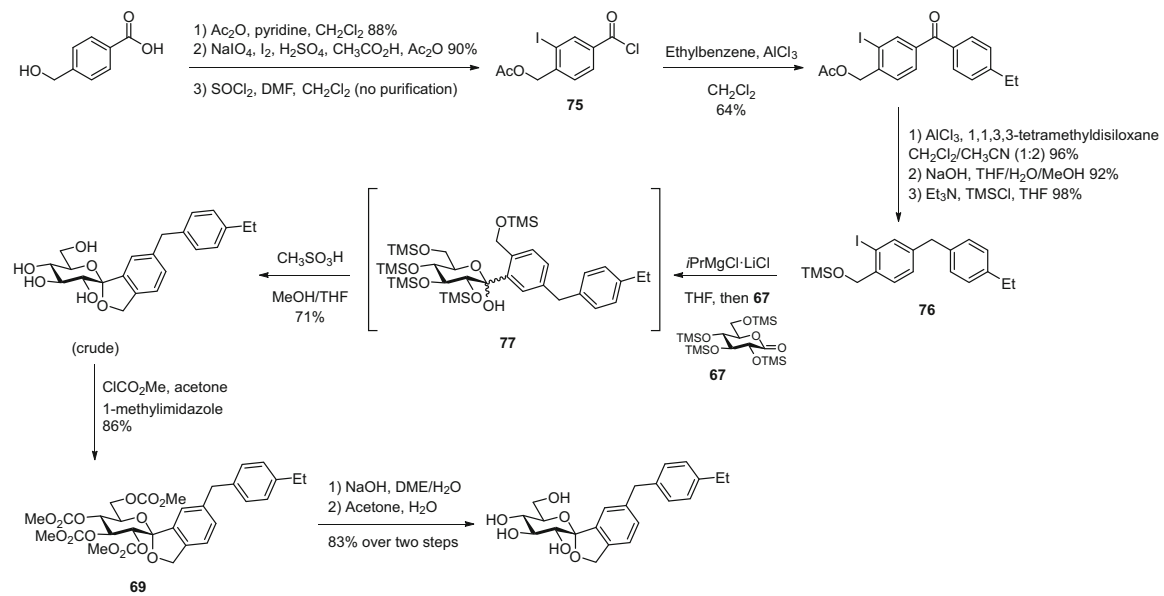

Scheme 24 Scalable $(\sim 100 \mathrm{~g})$ route toward tofogliflozin

These syntheses pointed out the different challenges going from lab-scale synthesis to multi-kilogram synthesis. Benzyl protecting groups were changed to silyl ether, avoiding a deprotection with hazardous hydrogen and heavy metal palladium. The introduction of carbonates as protecting groups allowed the crude tofogliflozin to be purified by crystallization. A difference in strategy was also discussed as the aglycon was formed after or before the $C$-glycosylation and the construction of the spiro-junction. 
These synthetic strategies bring out stereo- and/or regio-selectivity concerns for the construction of the spiro-junction $[59,61]$. In the reactions leading to $\mathbf{6 8}$ and $71 \rightarrow 72$, the spiro-cyclization to the five-membered ring was always preferred over the six-membered ring since the latter would be a highly strained 1,3-cyclophane. Regarding the stereoselectivity, the axial position of the oxygen atom is thermodynamically favored due to the anomeric effect.

\subsection{Synthesis of Spiro-Bicyclic Systems as Potential Glycogen Phosphorylase Inhibitors}

The control of hyperglycemia is of prime importance in the context of T2DM to avoid severe side effects such as retinopathy, nephropathy, or neuropathy [62]. Glucose is a source of energy for cells and is stocked in the liver as glycogen, a glucose- $\alpha-(1,4)$-glucose polymer with $\alpha-(1,6)$-glucose ramifications. Glycogen phosphorylase is the enzyme responsible for the depolymerization of glycogen by releasing a glucose-1-phosphate unit from the nonreducing end of the polymer. Thus, design and synthesis of glycogen phosphorylase inhibitors appear as a therapeutically relevant strategy for the treatment of hyperglycemia in type 2 diabetes [63-70]. Typical inhibitors are based on glucopyranoside scaffolds, and the spirobicyclic compounds are among the most potent inhibitors of this enzyme [65, 67, 71, 72].

\subsubsection{Radical-Mediated Cyclization (Path B)}

Glucosylidene-spiro-oxathiazoles 79 can be obtained by the radical-mediated cyclization of glucopyranosyl-thiohydroximates 78 (Scheme 25) with a 4:1 stereocontrol of the reaction in favor of the epimer $\mathbf{7 9}$ [73, 74]. Both epimers can be separated by chromatography. The deprotected derivatives of $\mathbf{7 9}$ were identified as sub-micromolar glycogen phosphorylase inhibitors [75, 76].

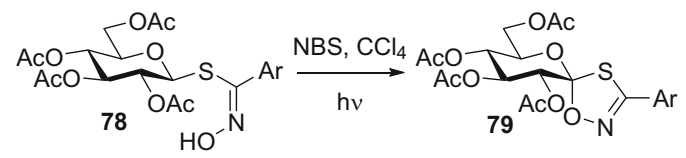

Scheme 25 Spiro-cyclization from a thiohydroximate to the corresponding glycosylidene-spirooxathiazole 


\subsubsection{1,3-Dipolar Cycloadditions (Path D)}

Stereoselective 1,3-dipolar cycloaddition of nitrile oxides to exo-glucals $\mathbf{4 1}$ could afford the corresponding spiro-isoxazolines 80 in high yields (Scheme 26) [77-80]. The stereoselectivity was in favor of the exclusive addition from the $\alpha$-face of the pyranoid ring. This spiro-isoxazoline bicyclic scaffold was later identified as a major pharmacophore motif for the submicromolar inhibition of glycogen phosphorylase as well as in vivo antihyperglycemic effects in the context of type 2 diabetes $[81,82]$.

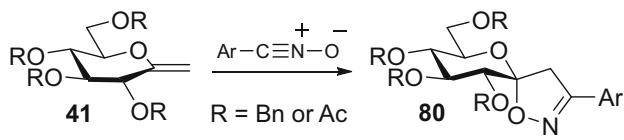

Scheme 26 Spiro-cyclization from an exo-glycal and nitrile oxide through 1,3-dipolar cycloaddition

\subsubsection{Ionic Ring Closures (Path D)}

Spiro-cyclization of the 1,2-aminoalcohol 81 using a Burgess-type reagent ( $t$-butyl $N$-(triethylammoniumsulfonyl)-carbamate) was accomplished in good yields leading to the corresponding spiro-sulfamide 82 (Scheme 27). After removal of the protecting groups (Boc/TFA and $\mathrm{Bn} / \mathrm{H}_{2}$ ), the spiro-glycosides were evaluated as glycogen phosphorylase inhibitors with encouraging micromolar activity [83]. The same strategy when applied to the 1,2-diol $\mathbf{8 3}$ afforded the corresponding spirosulfamidates 84 (Scheme 27) [84]. The stability of the Burgess reagent is poor, and reflux temperature was required to obtain optimized yields by shortening the reaction time to $2 \mathrm{~h}$ from $24 \mathrm{~h}$ at room temperature. The reaction was highly regio- and stereoselective for the $\alpha$-anomer. The deprotected spiro-glycosides obtained after acid-catalyzed removal of the carbamate and hydrogenolysis of the benzyl ethers provided weak but selective $\alpha$-glucosidase and amyloglucosidase inhibitors. Opposite $\beta$-configured spiro-sulfamidate $\mathbf{8 6}$ could be obtained in the 2-deoxy-glycoside series (Path B) from the $\beta$ - $C$-glycoside 85 by $\mathrm{Rh}$-mediated $\mathrm{C}-\mathrm{H}$ activation of the anomeric carbon-hydrogen bond followed by Boc-protection of the crude mixture to facilitate purifications (Scheme 27) [85]. Surprisingly, the $\alpha$-anomer of compound 85 decomposed under similar conditions. 
Scheme 27 Spirocyclization from 1,2-aminoalcohol and 1,2-diol or through anomeric $\mathrm{C}-\mathrm{H}$ activation
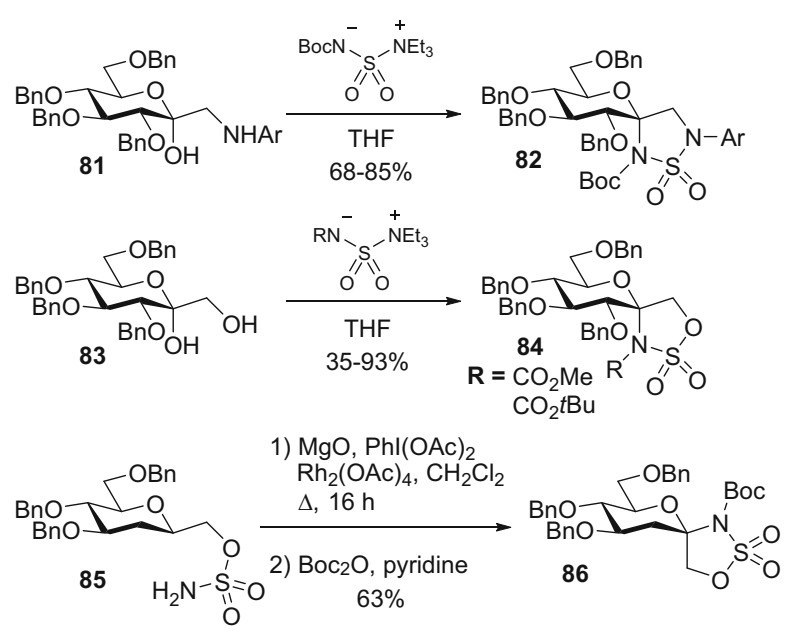

The $C$-(1-bromo-1-deoxy- $\beta$-D-glucopyranosyl) formamides were applied to numerous transformations leading to a series of five-membered spiro-bicyclic systems (Schemes 28 and 29). The $C$-(glucosyl)formamide 87a upon reaction with silver carbonate in acetone, used as a reagent and solvent, afforded the spiro-bicyclic compound 88a (Scheme 28) [86]. While silver ions were responsible of abstracting the halogen to generate the oxocarbenium intermediate, acetone acted as a nucleophile and added to the cation and intramolecular cyclization from the amide led to the spiro-bicyclic structure. A similar sequence could be performed from the benzoylated hemiacetal $\mathbf{8 9}$ through activation with triflic acid to generate the oxocarbenium intermediate in acetone leading to compound $\mathbf{8 8 b}$ as the benzoylated analogue of compound 88a (Scheme 28) [87]. A series of ketones has been used in this approach, and further debenzoylation could be performed affording inhibitor candidates for glycogen phosphorylase which unfortunately turned out to have no inhibitory effect.

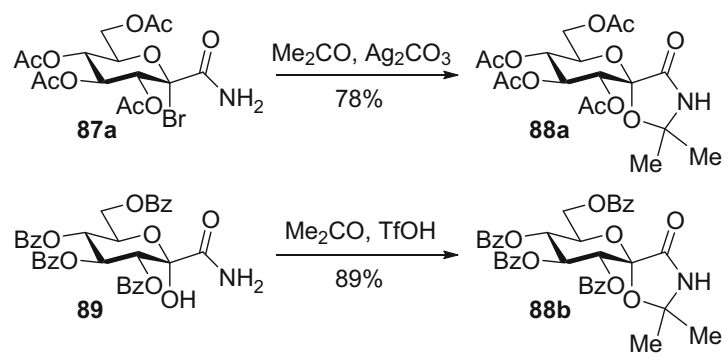

Scheme 28 Spiro-cyclization from $C$-(glucopyranosyl)formamides 


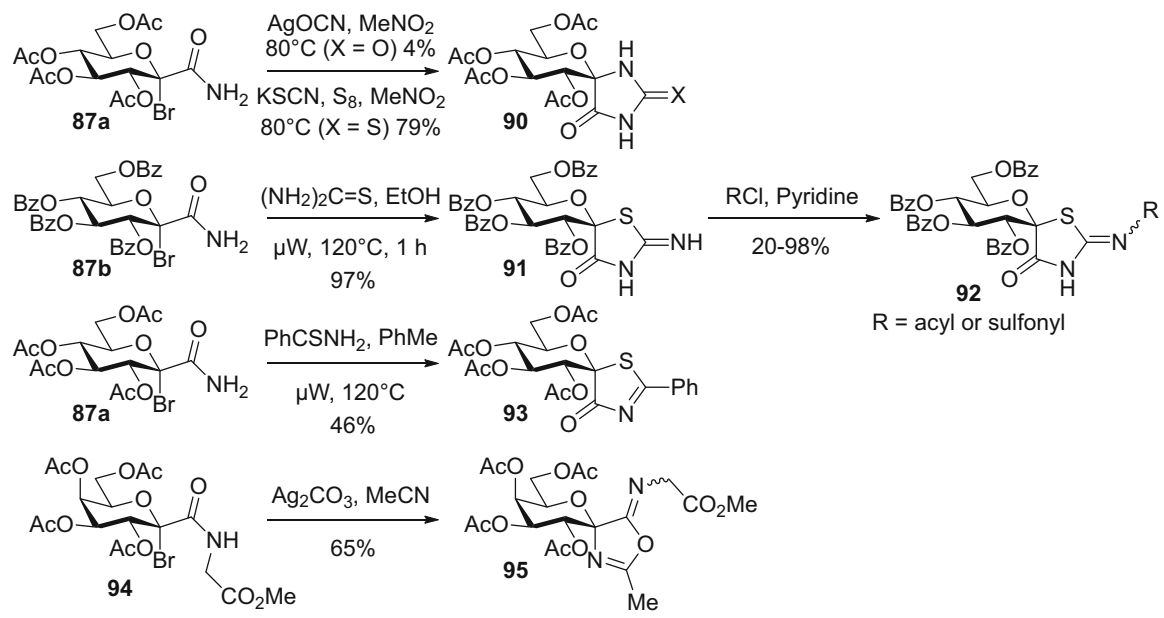

Scheme 29 Five-membered ring spiro-bicyclic glucosides as potential glycogen phosphorylase inhibitors

Spiro-cyclization of the $C$-(glucosyl)formamide 87a was achieved with silver cyanate to obtain the spiro-hydantoin $90(\mathrm{X}=\mathrm{O})$ in only $4 \%$ yield with a large portion of its spiro-epimer $(25 \%)$ and hydrolysis product hemiacetal $(53 \%)$ (Scheme 29) [88]. The deacetylated spiro-(thio)hydantoins 90 displayed micromolar inhibition toward glycogen phosphorylase. The same reaction performed with potassium isothiocyanate afforded the spiro-thiohydantoin $91(\mathrm{X}=\mathrm{S})$ as a single stereoisomer in good yield $(79 \%)$ although the presence of catalytic amount of elemental sulfur $\left(\mathrm{S}_{8}\right)$ was required to overcome radical-mediated pathways. When the benzoylated $C$-(glucosyl)formamide 87b was condensed with thiourea, the corresponding spiroiminothiazolidinone $\mathbf{9 1}$ was obtained in nearly quantitative yield with complete stereocontrol [89]. Further acylation of the imine moiety afforded a series of $\mathrm{N}$-substituted derivatives $\mathbf{9 2}$ as a mixture of isomers on the imine bond position. The debenzoylated compounds 91 and 92 were identified as micromolar inhibitors of glycogen phosphorylase. Similarly, when the acetylated $C$-(glucosyl) formamide 87a was reacted with thiobenzamide, the corresponding spiro-thiazolinone 93 was obtained in moderate yield (46\%) although with good stereocontrol [90]. The same synthesis performed from the benzoylated precursor $\mathbf{8 7 b}$ provided lower yields (14-18\%). Furthermore, deacetylation could only be performed in moderate yield (32\%) using lithium hydroxide. It was also observed that water addition to the spirothiazolinone 93 moiety modified the structure and prevented the evaluation as potential glycogen phosphorylase inhibitors. Finally, addition of nitrile to the $N$-substituted $C$-(glucosyl)formamide 94 in a Ritter-type reaction afforded spiroisoxazoline derivatives 95 which could then be further elaborated into anomeric glycosyl $\alpha$-amino acids [91]. Stereochemistry at the imine position could not be controlled, while the stereocontrol at the anomeric position was very good. 


\section{Conclusion and Perspectives}

Spiro-bicyclic compounds can be generated through a multitude of synthetic strategies within the organic chemist's arsenal. The present review has compiled a selection of examples highlighting the typical strategic routes for the creation of a spiro-junction at the anomeric position of hexopyranoses. The main strategies can be divided into intramolecular and intermolecular approaches, and a specific attention to the control of the stereochemistry at the anomeric center will be crucial. Cyclizations are typically performed through radical reactions, ring-closing metathesis ( RCM), C-H activation, and [3+2] or [2+2+2] cycloaddition reactions but also through acetalation under thermodynamic control.

Most of the synthetic strategies for which the configuration of the anomeric center is affected have moderate to very poor stereocontrol. If the anomeric configuration is set in the starting material, then no epimerization is usually observed. But if the anomeric position has to be activated (e.g., to oxocarbenium) under other synthetic pathways, the stereocontrol is typically moderate. Nevertheless, a good diastereoisomeric excess can be obtained when a thermodynamic equilibrium can be reached. Mixtures of epimers could be most often separated by chromatography or crystallization.

The synthesis of spiro-bicyclic glycosides has provided access to a large diversity of chemical scaffolds which proved useful in the modulation of biological targets' activity such as in the context of type 2 diabetes (SGLT2 and GP) or papulacandins as natural products with antifungal properties. Among these pharmaceutically relevant molecules, the gliflozins have reached the market, and tofogliflozin is now a drug marketed and used to treat hyperglycemia for type 2 diabetes patients.

The next developments for the synthesis of spiro-bicyclic glycopyranosides will most probably rely on the stereocontrol of the anomeric configuration. New and creative strategies are needed to result in even further complicated structures reaching different natural products in which the spiro-junction is a key feature. This will allow the discovery of unexpected molecular scaffolds to inhibit proteins toward drug candidates.

Acknowledgments The authors thank the Universite Claude Bernard Lyon 1 and the CNRS for financial support. MP is grateful to the Ministère de l'Enseignement supérieur et de la Recherche for a $\mathrm{PhD}$ stipend.

\section{References}

1. Vidal S (ed) (2019) Protecting groups: strategies and applications in carbohydrate chemistry. Wiley-VCH, Weinheim

2. Demchenko AV (ed) (2008) Handbook of chemical glycosylation: advances in stereoselectivity and therapeutic relevance. Wiley-VCH, Weinheim 
Anomeric Spiro-Annulated Glycopyranosides: An Overview of Synthetic...

3. Zulueta MML, Hung S-C (eds) (2016) Glycochemical synthesis: strategies and applications. Wiley-VCH, Weinheim

4. Chen G-R, Fei Zhong B, Huang X-T, Xie Y-Y, Xu J-L, Gola J, Steng M, Praly J-P (2001). Eur J Org Chem:2939-2946

5. Lambu MR, Hussain A, Sharma DK, Yousuf SK, Singh B, Tripathi AK, Mukherjee D (2014). RSC Adv 4:11023-11028

6. John Pal AP, Gupta P, Suman Reddy Y, Vankar YD (2010). Eur J Org Chem:6957-6966

7. Haudrechy A, Sinaÿ P (1992). Carbohydr Res 216:375-379

8. Yamanoi T, Oda Y, Muraishi H, Matsuda S (2008). Molecules 13:1840

9. Dondoni A, Marra A (2009). Tetrahedron Lett 50:3593-3596

10. Lin H-C, Chen Y-B, Lin Z-P, Wong FF, Lin C-H, Lin S-K (2010). Tetrahedron 66:5229-5234

11. Chen Y-B, Liu S-H, Hsieh M-T, Chang C-S, Lin C-H, Chen C-Y, Chen P-Y, Lin H-C (2016). J Org Chem 81:3007-3016

12. John Pal AP, Vankar YD (2010). Tetrahedron Lett 51:2519-2524

13. John Pal AP, Kadigachalam P, Mallick A, Doddi VR, Vankar YD (2011). Org Biomol Chem 9:809-819

14. Martín A, Salazar J, Suárez E (1995). Tetrahedron Lett 36:4489-4492

15. Betancor C, Dorta RL, Freire R, Prangé T, Suárez E (2000). J Org Chem 65:8822-8825

16. Martín A, Quintanal LM, Suárez E (2007). Tetrahedron Lett 48:5507-5511

17. Martín A, Pérez-Martín I, Suárez E (2009). Tetrahedron 65:6147-6155

18. Martín A, Pérez-Martín I, Suárez E (2005). Org Lett 7:2027-2030

19. Probst N, Grelier G, Ghermani N, Gandon V, Alami M, Messaoudi S (2017). Org Lett 19:5038-5041

20. Pezzotta J, Urban D, Guillot R, Doisneau G, Beau J-M (2014). Synlett 25:375-380

21. Briner K, Vasella A (1989). Helv Chim Acta 72:1371-1382

22. Blüchel C, Linden A, Vasella A (2001). Helv Chim Acta 84:3495-3502

23. Mangholz SE, Vasella A (1991). Helv Chim Acta 74:2100-2111

24. Vasella A, Waldraff CAA (1991). Helv Chim Acta 74:585-593

25. Somsák L, Praly J-P, Descotes G (1992). Synlett:119-120

26. Praly JP, El Kharraf Z, Descotes G (1990). Tetrahedron Lett 31:4441-4442

27. Blüchel C, Ramana CV, Vasella A (2003). Helv Chim Acta 86:2998-3036

28. Brand C, Rauch G, Zanoni M, Dittrich B, Werz DB (2009). J Org Chem 74:8779-8786

29. Vasella A, Witzig C, Waldraff C, Uhlmann P, Briner K, Bernet B, Panza L, Husi R (1993). Helv Chim Acta 76:2847-2875

30. Vasella A, Dhar P, Witzig C (1993). Helv Chim Acta 76:1767-1778

31. Lay L, Nicotra F, Panza L, Russo G (1995). Synlett:167-168

32. Schweizer F, Inazu T (2001). Org Lett 3:4115-4118

33. Zhang K, Schweizer F (2005). Synlett:3111-3115

34. Zhang K, Wang J, Sun Z, Nguyen D-H, Schweizer F (2007). Synlett:0239-0242

35. Zhang K, Mondal D, Zhanel GG, Schweizer F (2008). Carbohydr Res 343:1644-1652

36. Zhang K, Schweizer F (2009). Carbohydr Res 344:576-585

37. Praly JP, Brard L, Descotes G (1988). Tetrahedron Lett 29:2651-2654

38. Praly J-P, Kharraf ZE, Corringer P-J, Brard L, Descotes G (1990). Tetrahedron 46:65-75

39. Buchanan JG, Clelland APW, Wightman RH, Johnson T, Rennie RAC (1992). Carbohydr Res 237:295-301

40. Baddeley KL, Cao Q, Muldoon MJ, Cook MJ (2015). Chem Eur J 21:7726-7730

41. Zhang D, Ye D, Feng E, Wang J, Shi J, Jiang H, Liu H (2010). J Org Chem 75:3552-3557

42. McDonald FE, Zhu HYH, Holmquist CR (1995). J Am Chem Soc 117:6605-6606

43. Yamamoto Y, Yamashita K, Hotta T, Hashimoto T, Kikuchi M, Nishiyama H (2007). Chem Asian J 2:1388-1399

44. Bartolozzi A, Capozzi G, Falciani C, Menichetti S, Nativi C, Bacialli AP (1999). J Org Chem 64:6490-6494

45. Wrodnigg TM, Kartusch C, Illaszewicz C (2008). Carbohydr Res 343:2057-2066 
46. Gallas K, Pototschnig G, Adanitsch F, Stütz AE, Wrodnigg TM (2012). Beilstein J Org Chem 8:1619-1629

47. Denmark SE, Regens CS, Kobayashi T (2007). J Am Chem Soc 129:2774-2776

48. Denmark SE, Kobayashi T, Regens CS (2010). Tetrahedron 66:4745-4759

49. Song KS, Lee SH, Kim MJ, Seo HJ, Lee J, Lee SH, Jung ME, Son EJ, Lee M, Kim J, Lee J (2011). ACS Med Chem Lett 2:182-187

50. Harada N, Inagaki N (2012). J Diabetes Investig 3:352-353

51. Madaan T, Akhtar M, Najmi AK (2016). Eur J Pharm Sci 93:244-252

52. Washburn WN (2012) SGLT2 inhibitors in development. In: Jones RM (ed) New therapeutic strategies for type 2 diabetes: small molecule approaches. The Royal Society of Chemistry, Cambridge, pp 29-87

53. Bokor É, Kun S, Goyard D, Tóth M, Praly JP, Vidal S, Somsák L (2017). Chem Rev 117:1687-1764

54. Aguillón AR, Mascarello A, Segretti ND, de Azevedo HFZ, Guimaraes CRW, Miranda LSM, de Souza ROMA (2018). Org Proc Res Dev 22:467-488

55. Poole RM, Prossler JE (2014). Drugs 74:939-944

56. Murakata M, Ikeda T, Kimura N, Kawase A, Nagase M, Yamamoto K, Takata N, Yoshizaki S, Takano K (2009) Crystal of spiroketal derivative, and process for production thereof. WO2009154276

57. Kobayashi T, Sato T, Nishimoto M (2005) Spiroketal derivative and use thereof as diabetic medicine. US2009030006

58. Kobayashi T, Sato T, Nishimoto M (2006) Preparation of 1,1-anhydro-1-C-[2-(hydroxyalkyl) aryl]- $\beta$-D-glucopyranose compounds as SGLT2 inhibitors. WO2006080421A1

59. Ohtake Y, Emura T, Nishimoto M, Takano K, Yamamoto K, Tsuchiya S, Yeu SY, Kito Y, Kimura N, Takeda S, Tsukazaki M, Murakata M, Sato T (2016). J Org Chem 81:2148-2153

60. Yang X-D, Pan Z-X, Li D-J, Wang G, Liu M, Wu R-G, Wu Y-H, Gao Y-C (2016). Org Process Res Dev 20:1821-1827

61. Ohtake Y, Sato T, Kobayashi T, Nishimoto M, Taka N, Takano K, Yamamoto K, Ohmori M, Yamaguchi M, Takami K, Yeu SY, Ahn KH, Matsuoka H, Morikawa K, Suzuki M, Hagita H, Ozawa K, Yamaguchi K, Kato M, Ikeda S (2012). J Med Chem 55:7828-7840

62. Ross SA, Gulve EA, Wang M (2004). Chem Rev 104:1255-1282

63. Morral N (2003). Trends Endocrinol Metab 14:169-175

64. Baker DJ, Greenhaff PL, Timmons JA (2006). Expert Opin Ther Pat 16:459-466

65. Khan M (2007). Top Heterocycl Chem 9:33-52

66. Somsák L, Czifrák K, Tóth M, Bokor E, Chrysina ED, Alexacou KM, Hayes JM, Tiraidis C, Lazoura E, Leonidas DD, Zographos SE, Oikonomakos NG (2008). Curr Med Chem 15:2933-2983

67. Praly J-P, Vidal S (2010). Mini-Rev Med Chem 10:1102-1126

68. Henke BR (2012) Inhibition of glycogen phosphorylase as a strategy for the treatment of type 2 diabetes. In: Jones RM (ed) New therapeutic strategies for type 2 diabetes: small molecule approaches. The Royal Society of Chemistry, Cambridge, pp 324-365

69. Gaboriaud-Kolar N, Skaltsounis A-L (2013). Expert Opin Ther Pat 23:1017-1032

70. Donnier-Maréchal M, Vidal S (2016). Expert Opin Ther Pat 26:199-212

71. Somsák L, Nagy V, Hadady Z, Docsa T, Gergely P (2003). Curr Pharm Des 9:1177-1189

72. Somsák L (2011). C R Chim 14:211-223

73. Praly J-P, Boyé S, Joseph B, Rollin P (1993). Tetrahedron Lett 34:3419-3420

74. Elek R, Kiss L, Praly J-P, Somsák L (2005). Carbohydr Res 340:1397-1402

75. Somsák L, Nagy V, Vidal S, Czifrák K, Berzsényi E, Praly J-P (2008). Bioorg Med Chem Lett 18:5680-5683

76. Nagy V, Benltifa M, Vidal S, Berzsényi E, Teilhet C, Czifrák K, Batta G, Docsa T, Gergely P, Somsák L, Praly J-P (2009). Bioorg Med Chem 17:5696-5707

77. RajanBabu TV, Reddy GS (1986). J Org Chem 51:5458-5461 
78. Enderlin G, Taillefumier C, Didierjean C, Chapleur Y (2005). Tetrahedron Asymmetry 16:2459-2474

79. Benltifa M, Vidal S, Gueyrard D, Goekjian PG, Msaddek M, Praly J-P (2006). Tetrahedron Lett 47:6143-6147

80. Zhang P-Z, Li X-L, Chen H, Li Y-N, Wang R (2007). Tetrahedron Lett 48:7813-7816

81. Benltifa M, Hayes JM, Vidal S, Gueyrard D, Goekjian PG, Praly JP, Kizilis G, Tiraidis C, Alexacou KM, Chrysina ED, Zographos SE, Leonidas DD, Archontis G, Oikonomakos NG (2009). Bioorg Med Chem 17:7368-7380

82. Goyard D, Kónya B, Chajistamatiou AS, Chrysina ED, Leroy J, Balzarin S, Tournier M, Tousch D, Petit P, Duret C, Maurel P, Somsák L, Docsa T, Gergely P, Praly J-P, AzayMilhau J, Vidal S (2016). Eur J Med Chem 108:444-454

83. Tite T, Tomas L, Docsa T, Gergely P, Kovensky J, Gueyrard D, Wadouachi A (2012). Tetrahedron Lett 53:959-961

84. Benltifa M, Kiss MD, Garcia-Moreno MI, Mellet CO, Gueyrard D, Wadouachi A (2009). Tetrahedron Asymmetry 20:1817-1823

85. Toumieux S, Compain P, Martin OR (2005). Tetrahedron Lett 46:4731-4735

86. Somsák L, Kovács L, Gyóllai V, Ốsz E (1999). Chem Commun 7:591-592

87. Páhi A, Czifrák K, Kövér KE, Somsák L (2015). Carbohydr Res 403:192-201

88. Somsák L, Kovács L, Tóth M, Ốsz E, Szilágyi L, Györgydeák Z, Dinya Z, Docsa T, Tóth B, Gergely P (2001). J Med Chem 44:2843-2848

89. Czifrák K, Páhi A, Deák S, Kiss-Szikszai A, Kövér KE, Docsa T, Gergely P, Alexacou K-M, Papakonstantinou M, Leonidas DD, Zographos SE, Chrysina ED, Somsák L (2014). Bioorg Med Chem 22:4028-4041

90. Szabó KE, Kun S, Mándi A, Kurtán T, Somsák L (2017). Molecules 22:1760

91. Czifrák K, Gyóllai V, Kövér KE, Somsák L (2011). Carbohydr Res 346:2104-2112 